\title{
Abundance of Lacewing, Glenochrysa sp. (Neuroptera: Chrysopidae) in Forest at Various Stages of Recovery after Logging at Sungai Lalang Forest Reserve, Selangor, Malaysia
}

\begin{abstract}
A study on the abundance lacewing Glenochrysa sp. (Neuroptera:Chrysopidae) in a lowland dipterocarp forest at different stages of recovery after longing was carried out. The lacewings were sampled using sticky traps baited with eugenol. The traps were placed for one week at a three month interval over one year in a primary forest and forests of five and ten years after logging. The result shows that the abundance of Glenochrysa sp. varied with the stages of forest recovery after logging. The number Glenochrysa sp. was significantly higher in the logged over forests than in the primary forest. Even though the lacewing was present all year round, its abundance, however, was influenced by the composition of vegetation within the selected forests, availability of food resources as indicated homopteran abundance and amount of rainfall.
\end{abstract}

Keyword: Glenochrysa, eugenol, sticky trap, primary forest, logged forest 